\title{
Current status and conservation of the Endangered Przewalski's gazelle Procapra przewalskii, endemic to the Qinghai-Tibetan Plateau, China
}

\author{
Chunlin Li, Zhigang Jiang, Xiaoge Ping, Jing Cai, Zhangeiang You \\ CHUNWANG Li and YONGLIN Wu
}

\begin{abstract}
In 2008 Przewalski's gazelle Procapra przewalskii, endemic to the Qinghai-Tibetan Plateau, China, was recategorized from Critically Endangered to Endangered on the IUCN Red List. The species is still, however, threatened, and the human population and accompanying domestic livestock are increasing around Qinghai Lake. Here we provide up-to-date information on the distribution and population size of the species, evaluate its current conservation status and discuss the difficulties of protecting this gazelle species. We used both distance sampling and total counts to survey 16 sites where the species has been reported and found it at 13 of these, occupying a total area of c. $250 \mathrm{~km}^{2}$. Population size estimated from distance sampling $(1,635)$ and total counts $(1,544)$ was similar. About $20 \%$ of the gazelles located were in newly discovered areas for the species. The results indicate an overall growth in the population of Przewalski's gazelle since 2003, although some subpopulations have declined or been extirpated. In spite of conservation efforts Przewalski's gazelle is still threatened by habitat degradation and loss, habitat fragmentation, fencing, intensified competition with domestic livestock and predation. Further growth of this gazelle population is constrained by limited habitat availability and human-gazelle conflict. We recommend that management and conservation strategies need to incorporate comprehensive knowledge of the gazelle, longterm monitoring, and captive breeding of injured and orphaned gazelles to form a potential pool of individuals for future reintroductions to the historical range of the species outside the Qinghai Lake basin.
\end{abstract}

Keywords China, conservation status, distance sampling, human-wildlife conflict, Przewalski's gazelle, Procapra przewalskii, Qinghai Lake, total count

Chunlin Li, Zhigang Jiang (Corresponding author), Xiaoge Ping, Jing CaI, Zhangeiang You and Chunwang Li Key Laboratory of Animal Ecology and Conservation Biology, Institute of Zoology, Chinese Academy of Sciences, Beijing, China. E-mail jiangzg@ioz.ac.cn

YongLIN Wu Administration of the Qinghai Lake National Nature Reserve, Xining, Qinghai, China

Received 20 May 2010. Revision requested 28 June 2010.

Accepted 20 July 2010.

\section{Introduction}

D rzewalski's gazelle Procapra przewalskii, endemic to the Qinghai-Tibetan Plateau, China, was recategorized on the IUCN Red List from Critically Endangered to Endangered in 2008 (Jiang et al., 1995, 2003; Jiang, 2004; IUCN SSC Antelope Specialist Group, 2008). It is also listed as a Category I Key National Protected Wild Animal Species and regarded as a conservation priority, together with 12 other animal taxa and two plant taxa, in China (Jiang et al., 2003).

Przewalski's gazelle was once widespread in the west of China (Zhang \& Wang, 1964; Wang, 1991). But from the 1950 s onwards the species underwent significant declines and became confined to isolated patches around Qinghai Lake (Jiang et al., 1995, 2000, 2003). In 1986 the total population size was $<350$ (Jiang et al., 1995, 1996a,b) and it was considered the most threatened antelope species by Mallon \& Kingswood (2001). Research and conservation efforts for Przewalski's gazelle since the 1990s (Wei \& Jiang, 1998; Jiang et al., 2003, 2004; Jiang, 2004) resulted in an increase in the population, which was estimated to be 602 in 2003 (Ye et al., 2006). This gazelle species is, however, still threatened and the human population and accompanying domestic livestock are increasing around Qinghai Lake (Sun et al., 2007). Here we provide up-to-date information on the distribution and population size of the species, evaluate its current conservation status and discuss the difficulties of protecting this species of gazelle in China.

\section{Study area}

The study was conducted around Qinghai Lake. The Qinghai Lake National Nature Reserve, upgraded in 1997 from the Bird Island Nature Reserve (declared in 1975), covers the whole of Qinghai Lake and four subpopulations of Przewalski's gazelle (Bird Island, Sand Island, Ganzihe and Hargai; Fig. 1). The catchment area of the Lake is 29,661 $\mathrm{km}^{2}$ over altitudes of 3,194-5,174 $\mathrm{m}$. The climate of the area is semi-arid with dry, cold and long winters, a high level of solar radiation and a short frost-free period. Mean annual temperature is $-1.5^{\circ} \mathrm{C}$ and the lowest temperature recorded is $-40^{\circ} \mathrm{C}$. Mean total annual rainfall is $327-500 \mathrm{~mm}$ and mean annual evaporation is $1,300-2,000 \mathrm{~mm}$. Dominant 


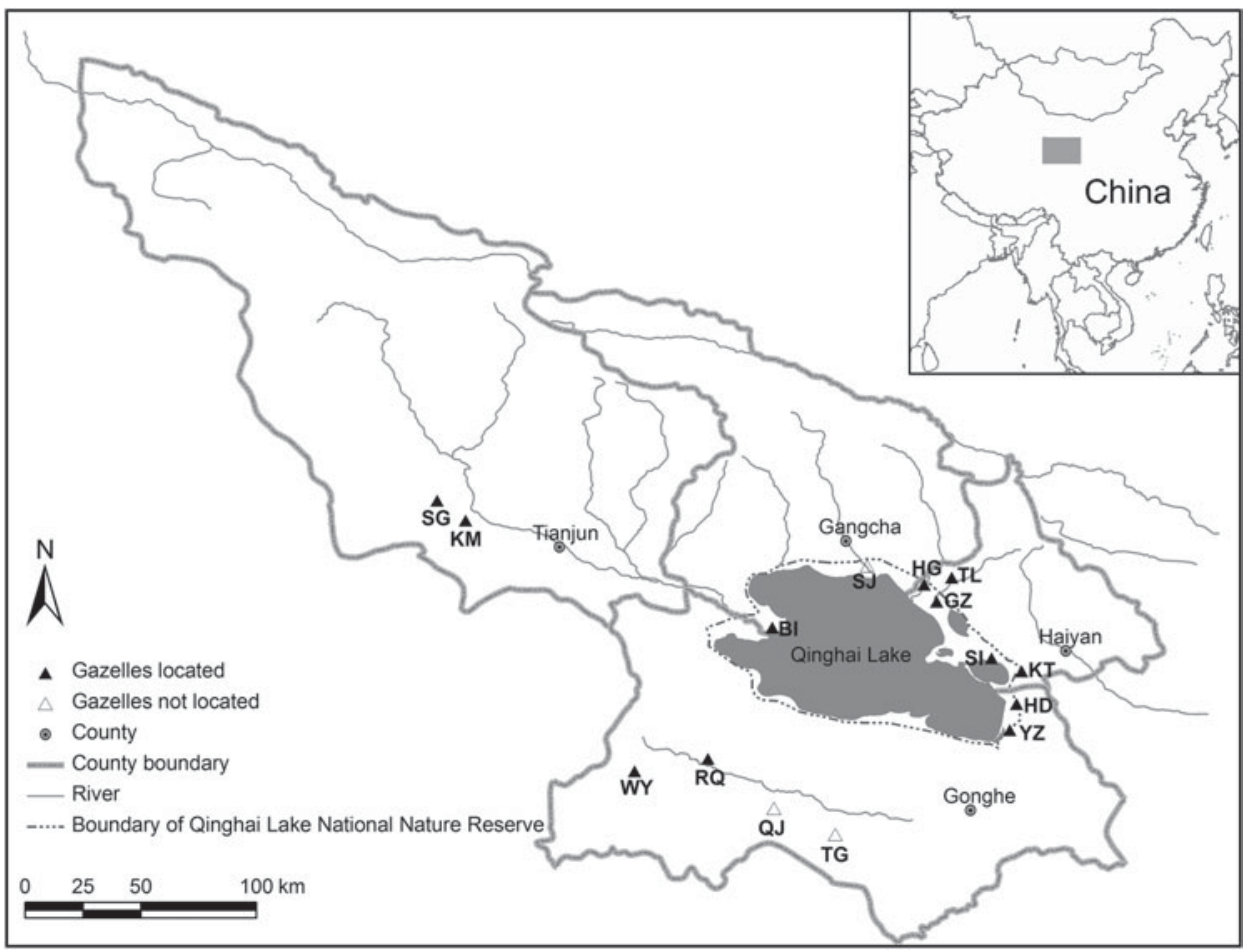

FIg. 1 Occurence of Przewalski's gazelle Procapra przewalskii at the 16 sites surveyed around Qinghai Lake: YZ, Yuanzhe; HD, Hudong; KT, Ketu; SI, Sand Island; GZ, Ganzihe (including GZs); HG, Hargai; TL, Taliexuanguo; BI, Bird Island; SG, Shengge; QJ, Qieji; SJ, Sanjiaocheng; KM, Kuairma; WY, Wayu; RQ, Ranquhu; TG, Tanggermu. The shaded rectangle on the inset indicates the location of the main map in China.

vegetation types include alpine meadow, alpine steppe, alpine shrub and psammophilous vegetation ( $\mathrm{Li} \&$ Zhao, 2008).

\section{Methods}

From March 2008 to July 2009 we conducted preliminary research, including a literature review and interviews with local wardens and pastoralists, to identify areas potentially inhabited by Przewalski's gazelle. We then carried out a field survey at the 16 sites identified, from July to September 2009 (60 days in total; Fig. 1). The surveys were conducted, on sunny days only, by two trained field workers, on foot, using binoculars and/or telescope, whilst walking at a mean speed of $2 \mathrm{~km} \mathrm{~h}^{-1}$ in early morning and late afternoon (the times when Przewalski's gazelle is most active). To avoid double-counting because of possible movement of gazelles between neighbouring subpopulations, we completed censuses at a site within 2-3 days and rechecked it after finishing the neighbouring census to ensure that no significant movement had occurred between the sites.

In our previous surveys (Jiang et al., 2000) we used the total count method to census Przewalski's gazelle but no confidence interval can be calculated for this method. In this study we therefore used both the total count method and distance sampling (Buckland et al., 2001; Thomas et al.,
2002); the latter was not used at the sites where there were too few gazelles or where the gazelles were aggregated in clusters of $>100$ (Table 1). For all surveys we recorded the date, time, location (with a global positioning system, GPS), cluster size, cluster composition, gazelle behaviour and vegetation type and, where appropriate, detection distance and bearing and estimated perpendicular distance for distance sampling. Detection distances were measured with a laser rangefinder (with an accuracy of $\pm 1 \mathrm{~m}$ over 30-4,000 m). Bearings were taken using the electronic compass function of a GPS.

For the total count method we travelled through the entire potential gazelle habitat at a site, ascending high points where available. To avoid repeat counts of the same individuals we avoided disturbing the gazelles, as far as possible, and noted their direction of movement. For distance sampling we first demarcated transect lines in areas of Przewalski's gazelle activity. We used a GPS to guide our walks along the transects. Repeated censuses of the same transects were conducted on different days to obtain at least 60 sightings for each subpopulation, as suggested by Buckland et al. $(1993,2001)$.

We recorded the locations, with a GPS, of residential sites, roads, perennial and artificial water sources, fences, and any remains and activity signs of Przewalski's gazelle. Heights of any fences were measured at nine sites (Yuanzhe, Hudong, Ketu, Sand Island, Ganzihe, Hargai, Shengge, 
TABLE 1 For each of the 16 sites (Fig. 1), the number of GPS points used to calculate the area occupied by each subpopulation of Przewalski's gazelle Procapra przewalskii, whether a site was newly discovered or not, the number of transects surveyed, their total length and total number of surveys, the number of groups sighted, and the survey methods used.

\begin{tabular}{|c|c|c|c|c|c|c|c|}
\hline Site & $\begin{array}{l}\text { No. of GPS } \\
\text { points }{ }^{1}\end{array}$ & $\begin{array}{l}\text { Newly } \\
\text { discovered? }\end{array}$ & $\begin{array}{l}\text { No. of } \\
\text { transects }\end{array}$ & $\begin{array}{l}\text { Transect } \\
\text { length }(\mathrm{km})\end{array}$ & $\begin{array}{l}\text { No. of } \\
\text { surveys }\end{array}$ & $\begin{array}{l}\text { No. of groups } \\
\text { sighted }\end{array}$ & $\begin{array}{l}\text { Survey } \\
\text { methods }^{2}\end{array}$ \\
\hline Yuanzhe & 78 & No & 2 & 4.7 & 16 & 68 & DS, TC \\
\hline Hudong & 153 & No & 1 & 5.1 & 12 & 109 & DS, TC \\
\hline Ketu & 161 & No & 2 & 7.7 & 5 & 66 & DS, TC \\
\hline Sand Island & 134 & No & 1 & 5.5 & 3 & 64 & DS, TC \\
\hline Ganzihe & 168 & No & 3 & 10.0 & 4 & 129 & DS, TC \\
\hline Hargai & 111 & No & 3 & 7.6 & 4 & 100 & DS, TC \\
\hline Shengge & 223 & No & 3 & 5.1 & 5 & 123 & DS, TC \\
\hline Kuairma & 76 & Yes & 1 & 5.2 & 4 & 60 & DS, TC \\
\hline Wayu & 94 & Yes & 3 & 10.6 & 3 & 57 & DS, TC \\
\hline $\mathrm{GZs}^{3}$ & 25 & No & 1 & 5.3 & 2 & 27 & $\mathrm{TC}$ \\
\hline Taliexuanguo & 16 & No & 1 & 5.0 & 4 & 7 & TC \\
\hline Sanjiaocheng & 0 & No & 2 & 6.2 & 2 & 0 & TC \\
\hline Bird Island & 32 & No & 2 & 6.0 & 2 & 8 & TC \\
\hline Ranquhu & 12 & Yes & 1 & 3.2 & 2 & 2 & TC \\
\hline Qieji & 0 & No & 2 & 10.5 & 2 & 0 & TC \\
\hline Tanggermu & 0 & No & 2 & 9.6 & 2 & 0 & TC \\
\hline Total & 1,283 & & 30 & 107.3 & 72 & 144 & 820 \\
\hline
\end{tabular}

${ }^{1}$ Number of GPS points of activity signs, sightings and faeces (including records during the current and previous field work, covering all seasons in 2008 and spring in 2009)

${ }^{2} \mathrm{DS}$, distance sampling; TC, total count

${ }^{3} \mathrm{GZs}$ is a small area within Ganzihe where Przewalski's gazelle was foraging in large herds and thus where distance sampling was not appropriate (S. Buckland, pers. comm.)

Kuairma and Wayu) where there are fences in the gazelle's habitat. We collected any remains of Przewalski's gazelles and recorded the gender, age, cause of death and location, with a GPS.

Census data for distance sampling were analysed with Distance v. 6.0 (Thomas et al., 2009). The data were 5\% right-truncated and the model with the lowest Akaike's Information Criterion was selected as the best fit (Akaike, 1973; Buckland et al., 2001). Calves were excluded from the analysis to avoid underestimation of the detection probability, caused by a lower detection probability for some orphaned calves (Thomas et al., 2002). We estimated the number of calves directly from the total count and calculated the ratios of calves to adult females using the data from repeated surveys. Locations of sightings and faeces of Przewalski's gazelle (including records during the current and previous field work covering all seasons in 2008 and spring in 2009) were used to calculate the species' range using the minimum convex polygon (MCP) and 95\% fixed kernel methods in the Animal Movement Analysis extension for ArcView v. 3.3 (ESRI, Redlands, USA). The density of roads, fences and residential sites were calculated in ArcView v. 3.3 using the GPS locations of these anthropogenic facilities.

Interviews with local herdsmen and officials in Qinghai Lake National Nature Reserve provided information about domestic livestock, illegal poaching, predation risk from wolves Canis lupus and Tibetan fox Vulpes ferrilata and conservation actions for Przewalski's gazelle. Provincial statistical yearbooks and local governments were consulted for socio-economic information about people living around Qinghai Lake. Data from the Fifth National Census (2001) were used to map human population density around the Lake, using the Geostatistical Analyst module of ArcGIS v. 9.2 (ESRI, Redlands, USA). The severities of the potential threats to Przewalski's gazelle were estimated for each subpopulation based on data collected during preliminary interviews and our field work.

\section{Results}

\section{Distribution and population size}

We located Przewalski's gazelle in 13 of the 16 sites surveyed, in a total area of c. $250 \mathrm{~km}^{2}$ (Table 2). Movement of gazelles between the surveyed sites is impeded by geographical and human-induced isolation (Fig. 1). We surveyed a total length of $339.5 \mathrm{~km}$ and counted 776 groups of gazelles at the nine sites where distance sampling was employed and 44 groups at the other seven sites. No sightings were recorded at a distance $>1.4 \mathrm{~km}$. In the total counts we recorded 1,544 gazelles. The adult population size estimated with Distance at the nine sites where distance 
TABle 2 Population size and composition, and area occupied by, and density of, adult Przewalski's gazelle at each of the 16 surveyed sites (Fig. 1).

\begin{tabular}{|c|c|c|c|c|c|c|c|c|c|}
\hline \multirow[b]{2}{*}{ Site } & \multicolumn{5}{|c|}{ Population $^{1}$} & \multicolumn{2}{|c|}{$\begin{array}{l}\text { Area occupied } \\
\left(\mathrm{km}^{2}\right)^{2}\end{array}$} & \multicolumn{2}{|c|}{$\begin{array}{l}\text { Adult density } \pm \text { SE } \\
\left(\mathrm{km}^{-2}\right)^{3}\end{array}$} \\
\hline & Total & Adults & Calves & $\begin{array}{l}\text { Mean no. of calves per } \\
\text { adult female } \pm \text { SE }\end{array}$ & $\begin{array}{l}\text { Estimated no. of } \\
\text { adults } \pm \text { SE }\end{array}$ & MCP & $\begin{array}{l}95 \% \text { fixed } \\
\text { kernel }\end{array}$ & Estimated & Calculated \\
\hline Yuanzhe & 50 & 41 & 9 & $0.39 \pm 0.04$ & $26 \pm 5$ & 4.7 & 6.6 & $3.1 \pm 0.6$ & $5.5 \pm 1.1$ \\
\hline Hudong & 101 & 77 & 24 & $0.33 \pm 0.04$ & $126 \pm 17$ & 8.0 & 6.0 & $12.3 \pm 1.7$ & $15.8 \pm 2.1$ \\
\hline Ketu & 88 & 62 & 26 & $0.55 \pm 0.10$ & $72 \pm 27$ & 11.2 & 15.7 & $7.4 \pm 2.8$ & $6.4 \pm 2.4$ \\
\hline Sand Island & 105 & 80 & 25 & $0.52 \pm 0.04$ & $86 \pm 17$ & 11.9 & 16.9 & $5.7 \pm 0.9$ & $7.2 \pm 1.4$ \\
\hline Ganzihe & 185 & 127 & 58 & $0.54 \pm 0.04$ & $153 \pm 78$ & 90.7 & 62.4 & $8.0 \pm 4.1$ & $1.7 \pm 0.9$ \\
\hline Hargai & 237 & 167 & 70 & $0.63 \pm 0.01$ & $186 \pm 126$ & 10.4 & 11.6 & $14.9 \pm 10.1$ & $17.9 \pm 12.1$ \\
\hline Shengge & 141 & 104 & 37 & $0.50 \pm 0.01$ & $97 \pm 28$ & 10.9 & 15.9 & $7.4 \pm 2.1$ & $8.9 \pm 2.6$ \\
\hline Kuairma & 172 & 129 & 43 & $0.50 \pm 0.03$ & $122 \pm 24$ & 7.5 & 12.3 & $10.1 \pm 2.0$ & $16.3 \pm 3.2$ \\
\hline Wayu & 88 & 62 & 26 & $0.49 \pm 0.08$ & $72 \pm 33$ & 54.7 & 55.3 & $3.2 \pm 1.5$ & $1.3 \pm 0.6$ \\
\hline GZs & 251 & 173 & 78 & $0.60 \pm 0.05$ & 173 & 10.0 & 10.0 & & 17.3 \\
\hline Sanjiaocheng & 0 & 0 & 0 & & 0 & 0 & 0 & & 0 \\
\hline Taliexuanguo & 63 & 53 & 10 & $0.36 \pm 0.06$ & 53 & 5.0 & 5.0 & & 10.6 \\
\hline Bird Island & 27 & 21 & 6 & $0.29 \pm 0.02$ & 21 & 5.0 & 5.0 & & 4.2 \\
\hline Ranquhu & 36 & 27 & 9 & $0.33 \pm 0.01$ & 27 & 20.0 & 20.0 & & 1.4 \\
\hline Qieji & 0 & 0 & 0 & & 0 & 0 & 0 & & 0 \\
\hline Tanggermu & 0 & 0 & 0 & & 0 & 0 & 0 & & 0 \\
\hline Total & 1,544 & 1,123 & 421 & $0.46 \pm 0.04$ & 1,214 & 250.0 & 242.7 & & 4.9 \\
\hline
\end{tabular}

${ }^{1}$ Total, numbers of adults and calves, and mean number of calves per female were obtained from the total counts; the estimated no. of adults was determined from distance sampling.

${ }^{2}$ Calculated with both the minimum convex polygon (MCP) and a 95\% fixed kernel. Area occupied by the species at GZs, Taliexuanguo, Bird Island and Ranquhu was estimated from our knowledge and experience as the number of GPS points of signs of Przewalski's gazelle activities were $<50$.

${ }^{3}$ Estimated: densities of adults at sites where distance sampling was used, estimated by Distance. Calculated: density determined from the estimated number of adults divided by the area of the MCP of the area occupied by the species at each site.

sampling was employed was 940. Adding the number of calves recorded, the estimated population size of these sites was 1,258 . Adding to this the total count for the seven sites where only the total count method was used gives an estimated total population size of 1,635 .

About 300 individuals (c. 20\%) were detected at three sites where the gazelle has not previously been reported: Kuairma, Wayu and Ranquhu (discovered in 2004, 2008 and 2009, respectively). The density of adults estimated with the total count method and distance sampling was 4.5 and $4.9 \mathrm{~km}^{-2}$, respectively. Based on our total counts and those reported by $\mathrm{Ye}$ et al. (2006) the mean annual population growth rate was $6.17 \%$ although not all subpopulations increased (Table 3). Local pastoralists indicated that there may be a few gazelles in Sanjiaocheng and Qieji but we did not find any signs of gazelles there. We did not find any signs of gazelles at Tanggermu and local residents indicated they had not seen any there since 2003 .

\section{Potential threats}

The intensity of the potential threats varied between sites (Table 3). The human population around Qinghai Lake has increased tenfold and livestock fourfold in the previous
5 decades (Fig. 2). The height of fences ranged from $100.3 \pm$ SE 13.7 to $111.9 \pm \mathrm{SE} 12.0 \mathrm{~cm}$ and the length of fences per $\mathrm{km}^{2}$ of grassland was $1.16-6.64 \mathrm{~km}$. We often found (in c. 100 observations) that Przewalski's gazelle was reluctant or unable to cross fences. Even though local pastoralists reported occasional movements of gazelles between Ganzihe, GZs and Hargai (through four railway passages), Shengge and Kuairma, and Wayu and Ranquhu, we did not witness movements between other subpopulations. The increased human population and domestic livestock now restrict the gazelle to patches of low human density (Fig. 3). Poaching has not been a key threat following the extensive confiscation of guns by the government in the 1990s. In the last 10 years local pastoralists only witnessed one incident of poaching, for meat, in each of Yuanzhe, Hudong and Wayu (Table 2). Predation, however, is still a threat. We observed a mean of c. 2.4 remains of Przewalski's gazelles per subpopulation killed by wolves during the 6o-day field census, and remains of calves were found near burrows of Tibetan fox in Yuanzhe (one calf), Ketu (two), Ganzihe (four) and Shengge (one). Field patrols of the Qinghai Lake Nature Reserve at Ganzihe from October 2009 to April 2010 recorded the deaths of 32 Przewalski's gazelles killed by wolves. 
TABLE 3 Population trends of Przewalski's gazelle and the degree of the main threats (habitat fragmentation, human density, effect of fences, habitat degradation, competition with livestock, predation and poaching) to the species at the 16 sites surveyed. The degree of impact of the threats was categorized as no occurrence $(\mathrm{N})$, low $(+)$, medium $(++)$ and high $(+++)$.

\begin{tabular}{|c|c|c|c|c|c|c|c|c|c|}
\hline \multirow[b]{2}{*}{ Site } & \multirow{2}{*}{$\begin{array}{l}\text { Population } \\
\text { trend }^{1}\end{array}$} & \multicolumn{2}{|c|}{$\underline{\text { Habitat fragmentation }^{2}}$} & \multirow{2}{*}{$\begin{array}{l}\text { Human } \\
\text { density }\end{array}$} & \multirow{2}{*}{$\begin{array}{l}\text { Effect of } \\
\text { fences }\end{array}$} & \multirow{2}{*}{$\begin{array}{l}\text { Habitat } \\
\text { degradation }\end{array}$} & \multirow{2}{*}{$\begin{array}{l}\text { Competition with } \\
\text { livestock }^{8}\end{array}$} & \multirow[b]{2}{*}{ Predation $^{9}$} & \multirow[b]{2}{*}{ Poaching $^{10}$} \\
\hline & & By fences ${ }^{3}$ & By roads ${ }^{4}$ & & & & & & \\
\hline Yuanzhe & Decline & +++ & ++ & +++ & ++ & + & +++ & ++ & + \\
\hline Hudong & Increase & +++ & ++ & +++ & +++ & +++ & ++ & +++ & + \\
\hline Ketu & Decline & + & +++ & + & + & +++ & + & +++ & $\mathrm{N}$ \\
\hline Sand Island & Increase & ++ & +++ & + & ++ & +++ & ++ & ++ & $\mathrm{N}$ \\
\hline Ganzihe & Increase & ++ & ++ & ++ & +++ & + & ++ & +++ & $\mathrm{N}$ \\
\hline Hargai & Increase & $\mathrm{N}$ & ++ & $\mathrm{N}$ & + & + & $\mathrm{N}$ & ++ & $\mathrm{N}$ \\
\hline Shengge & Increase & + & + & + & + & + & ++ & ++ & $\mathrm{N}$ \\
\hline Kuairma & Unknown & + & + & + & + & + & ++ & ++ & $\mathrm{N}$ \\
\hline Wayu & Unknown & + & + & ++ & + & ++ & +++ & ++ & + \\
\hline $\mathrm{GZs}$ & Increase & + & ++ & ++ & + & + & ++ & ++ & $\mathrm{N}$ \\
\hline Sanjiaocheng & Decline & ++ & ++ & ++ & $\mathrm{N}$ & + & ++ & + & $\mathrm{N}$ \\
\hline Taliexuanguo & Decline & + & ++ & +++ & + & +++ & ++ & + & $\mathrm{N}$ \\
\hline Bird Island & Stable & + & +++ & + & + & +++ & + & ++ & $\mathrm{N}$ \\
\hline Ranquhu & Unknown & $\mathrm{N}$ & + & + & + & ++ & ++ & ++ & $\mathrm{N}$ \\
\hline Qieji & Decline & + & + & +++ & $\mathrm{N}$ & +++ & ++ & ++ & $\mathrm{N}$ \\
\hline Tanggermu & Decline & + & ++ & +++ & $\mathrm{N}$ & +++ & ++ & ++ & $\mathrm{N}$ \\
\hline
\end{tabular}

${ }^{1}$ Derived from a comparison between the current study and Ye et al. (2006).

${ }^{2}$ Mainly caused by fences, roads and railways.

${ }^{3}$ Density of fences $\left(\mathrm{km} \mathrm{km}^{-2}\right):+, 0<2 ;++, 2 \leq 4 ;+++, \geq_{4}$.

+ , only a few small roads used by pastoralists; ++ , one highway or railway surrounding only one side of the area; +++ , one highway or railway surrounding more than one side of the area.

${ }^{5}$ Number of families $\mathrm{km}^{-2}:+, 0<0.25 ;++, 0.25 \leq 0.75 ;+++\geq 0.75$.

${ }^{6}$ Number of Przewalski's gazelles killed or injured per year by fences:,$+ 0<2 ;++, 2 \leq 5 ;+++, \geq 5$

${ }_{+}^{+}$, High habitat quality with no desertification; ++ , low habitat quality with slight desertification; +++ , severe desertification (Tang \& Wang, 2009).

${ }^{8}$ Number of livestock km ${ }^{-2}:+, 0<50 ;++, 50 \leq 100 ;+++, \geq 100$

${ }^{9}$ Number of observed remains of Przewalski's gazelles killed by wolf or Tibetan fox:,$+ 0<2 ;++, 2 \leq 4 ;+++, \geq 4$

${ }^{10}$ Information from informal interviews with local pastoralists and wardens: + , one occurrence in previous year; $\mathrm{N}$, no occurrence in previous year. 


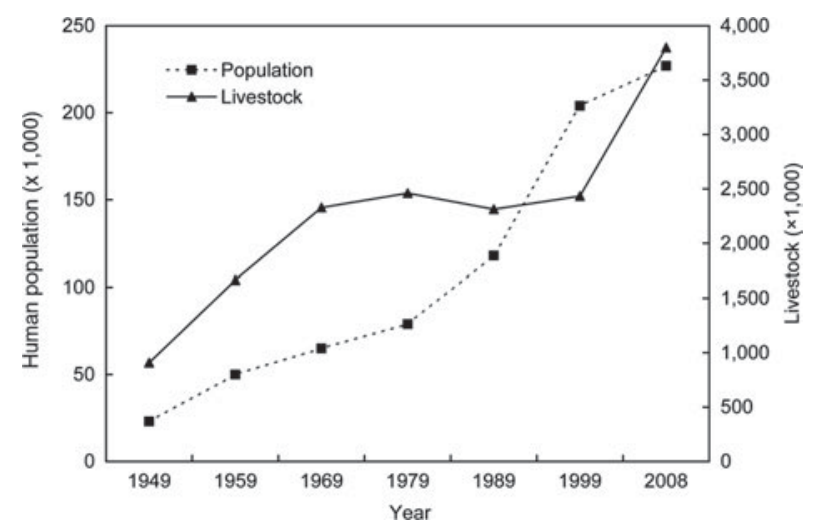

FIG. 2 Growth of the human population and livestock in four counties (Haiyan, Gangcha, Gonghe and Tianjun) combined around Qinghai Lake (Fig. 1).

\section{Conservation actions}

Wardens of Qinghai Lake National Nature Reserve conduct regular field patrols. Poaching is prohibited and this is enforced with the aid of local forestry police. Sixteen fence passages (breaches of 4- $\mathrm{m}$ in length) and eight artificial pools were established and $20 \mathrm{~km}$ of wire fences were lowered or removed in 2008 under the auspices of the EU-China Biodiversity Programme. However, we did not see any signs of Przewalski's gazelles using the water pools or fence passages during our surveys. The Wildlife Rescue Center in Bird Island has rescued 20 Przewalski's gazelles since its establishment in 2002 and two reproductive females in the Wildlife Rescue Center successfully produced six calves from 2002 to 2008 . However, a viable population is not yet established in captivity.

\section{Discussion}

\section{Population status and potential threats}

The difference in the estimate of the total population of Przewalski's gazelles using only the total count $(1,544)$ and the total count plus distance sampling $(1,635)$ was small, suggesting acceptably accurate results. Excluding the newly reported subpopulations at Kuairma, Wayu and Ranquhu, the mean annual population growth rate was $6.17 \%$ since 2003. The increase in the density estimated by the total count method (4.5 adults km $\mathrm{km}^{-2}$ vs $2.34 \mathrm{~km}^{-2}$ in 2001 and $0.82 \mathrm{~km}^{-2}$ in 2004) may partly result from differences in estimating area rather than any absolute population size increase (Lei et al., 2001; Liu \& Jiang, 2004). The calf to adult female ratio appears to be correlated with subpopulation size (Table 2), and this requires further investigation.

The total number of Przewalski's gazelle remains small despite the growth in the population. As the human population of the area has increased, desertification within the range of Przewalski's gazelle has increased fourfold since
1956 because of overgrazing (Tang \& Wang, 2009). Together with roads, railways and human activities, fences fragment the grassland habitat of the gazelle (Li et al., 2009a; Tang \& Wang, 2009). Habitat fragmentation in a degraded matrix prevents gene flow between subpopulations and results in reduced genetic diversity (Gibbs, 2001; Lei et al., 2003; Dixo et al., 2009). Fences not only fragment habitat but also injure and kill gazelles (Fox et al. 2009; Mallon \& Jiang, 2009) and can prevent them escaping from predators; the remains of gazelles killed by wolves have been found near such fences (You Z. et al., unpubl. data). However, it is impossible to remove fences in such a large area because they are convenient for paddock management (Banks et al., 2003). Spatial overlap and food competition (c. $80 \%$ overlap) with domestic livestock, especially during food-limited seasons (Liu \& Jiang, 2004; Li et al., 2008) are intensified as the number of livestock increases around Qinghai Lake. Additionally, possible transmission of infectious diseases between wild animals and domestic livestock could be of concern (Morgan et al., 2006; Smith et al., 2009).

Following the cessation of hunting in the 1990s (Harris, 2008) predation has become one of the most serious threats to the survival of Przewalski's gazelle because of the growth of the wolf population around Qinghai Lake (Jiang et al., 2000). Predation on the physically drained male adults in the rutting season, lambing females and calves significantly affects growth of the gazelle population (Jiang, 2004, 2008). In another study in three of the locations where Przewalski's gazelle occurs we found that depredation of livestock is a growing problem that local pastoralists attribute to the increasing population of wolf and Tibetan fox (Li C. et al., unpubl. data). Appropriate controls on growth of the wolf and fox population need to be considered.

There are considerable effects of vigilance costs on survival, reproductive success and abundance in other gazelle species (Manor \& Saltz, 2004; Preisser et al., 2005; Gingold et al., 2009). Monitoring threats from predators, human intrusions and shepherd dogs may reduce access to resources, mates and reproductive success (Illius \& Fitzgibbon, 1994; Fortin et al., 2004; Li et al., 2009b). Although there is little information about any such effects on Przewalski's gazelle this subject warrants investigation.

\section{Conservation status}

The population growth of Przewalski's gazelle since the 1980 s can be mainly attributed to the establishment of protected areas and a nationwide prohibition on poaching. Four subpopulations (Bird Island, Sand Island, Ganzihe and Hargai), with c. $59 \%$ of the total population of Przewalski's gazelle, are protected within Qinghai Lake National Nature Reserve and, except for that of Bird Island, have increased within the last 2 decades (Jiang et al., 1995; Ye et al., 2006). 


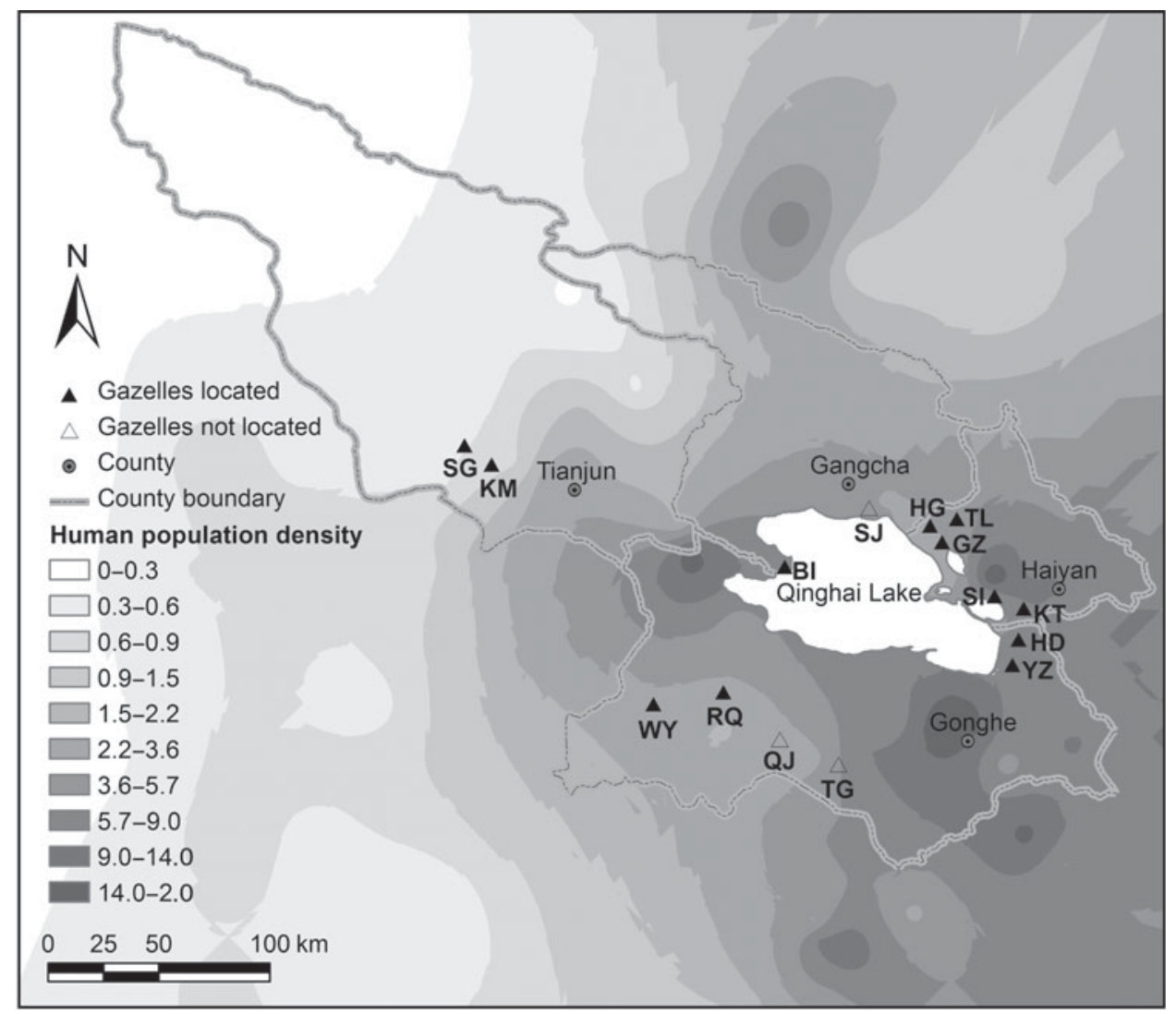

FIG. 3 Human population density (individuals per $\mathrm{km}^{2}$ ) around Qinghai Lake and distribution range of Przewalski’s gazelle.

Only three cases of poaching for meat have been observed by local pastoralists outside the Reserve in the last 10 years. Following the raising of local conservation awareness the majority of local pastoralists support the conservation of Przewalski's gazelle (Hu et al., 2010).

However, the conservation of the c. $41 \%$ of the population of Przewalski's gazelle that live outside the Reserve needs to be addressed. New conservation facilities such as the fence passages and artificial water pools, established in 2008, are not yet being used by the gazelles but they may require further time to become accustomed to these structures. Although local involvement plays an important role in preserving threatened species (Maroney, 2005) intensified conflict between people and Przewalski's gazelle will be unavoidable if the population of the gazelle continues to increase. The grazing pastures around Qinghai Lake are contracted to local pastoralists by the state for 70 years and Qinghai Lake National Nature Reserve has no right to manage the paddocks or to control livestock grazing. More efforts will need to be made to resolve the intensifying conflict between people and Przewalski's gazelle. Of geographical distance, topography, human settlement, roads and railways, Yang et al. (2011) found that human settlement is the main factor shaping the genetic differentiation of Przewalski's gazelle. This further illustrates the importance of collaboration with the local community.

\section{Conservation recommendations}

Despite the recategorization of Przewalski's gazelle on the IUCN Red List from Critically Endangered to Endangered because the number of mature individuals was estimated to be 350-400 or greater (Jiang et al., 1995, 2003; Jiang, 2004; IUCN SSC Antelope Specialist Group, 2008), the survival of the species is not yet secure. There are two principal emerging challenges: limitation of available habitat and human-gazelle conflict. We make the following recommendations for the long-term conservation of the species. Firstly, management and conservation strategies need to incorporate comprehensive knowledge of the gazelle, including that of local communities. Secondly, the long-term monitoring needs to continue. Thirdly, captive breeding of injured and orphaned gazelles should be instigated, to form a potential pool of individuals for future reintroductions to the historical range of the species outside the Qinghai Lake basin.

\section{Acknowledgements}

We appreciate the support of the Administration of Qinghai Lake National Nature Reserve and the Wildlife and Nature Reserve Management Bureau of Qinghai Province. We are grateful to Tsranben, Nuodetsran and Huaqingjia for their 
assistance in the field and to Dr Steve Buckland for help in using distance sampling. Our work was supported by Science and Technology Supporting Project of MOST (2008BAC 39 B04), State Forestry Administration, and the Sir Peter Scott Fund of the SSC/IUCN.

\section{References}

Akaike, H. (1973) Information theory and an extension of the maximum likelihood principle. In Proceedings of the 2nd International Symposium on Information Theory (eds B. Petrv \& F. Csaki), pp. 267-281. Akademiai Kiado, Budapest, Hungary.

Banks, T., Richard, C., Li, P. \& YAN, Z. (2003) Community-based grassland management in Western China-rationale, pilot project experience, and policy implications. Mountain Research and Development, 23, 132-140.

Buckland, S.T., Anderson, D.R., Burnham, K.P. \& Laake, J.L. (1993) Distance Sampling: Estimating Abundance of Biological Populations. Chapman and Hall, London, UK.

Buckland, S.T., Anderson, D., Burnham, K., Laake, J., Borchers, D. \& Thomas, L. (2001) Introduction to Distance Sampling: Estimating Abundance of Biological Populations. Oxford University Press, New York, USA.

Dixo, M., Metzger, J., Morgante, J. \& Zamudio, K. (2009) Habitat fragmentation reduces genetic diversity and connectivity among toad populations in the Brazilian Atlantic Coastal Forest. Biological Conservation, 142, 1560-1569.

Fortin, D., Boyce, M., Merrill, E. \& Fryxell, J. (2004) Foraging costs of vigilance in large mammalian herbivores. Oikos, 107, 172-180.

Fox, J., Dhondup, K. \& DorjI, T. (2009) Tibetan antelope Pantholops hodgsonii conservation and new rangeland management policies in the western Chang Tang Nature Reserve, Tibet: is fencing creating an impasse? Oryx, 43, 183-190.

GibBs, J. (2001) Demography versus habitat fragmentation as determinants of genetic variation in wild populations. Biological Conservation, 100, 15-20.

Gingold, G., Yom-Tov, Y., Kronfeld-Schor, N. \& Geffen, E. (2009) Effect of guard dogs on the behavior and reproduction of gazelles in cattle enclosures on the Golan Heights. Animal Conservation, 12, 155-162.

Harris, R. (2008) Wildlife Conservation in China: Preserving the Habitat of China's Wild West. M.E. Sharpe, Armonk, USA.

Hu, J., Ping, X., CaI, J., Li, Z., Li, C. \& Jiang, Z. (2010) Do local communities support the conservation of endangered Przewalski's gazelle? European Journal of Wildlife Research, 56, 551-560.

Illius, A. \& Fitzgibion, C. (1994) Costs of vigilance in foraging ungulates. Animal Behaviour, 47, 481-484.

IUCN SSC Antelope Specialist Group (2008) Procapra przewalskii. In IUCN Red List of Threatened Species v. 2010.4. Http:// www.iucnredlist.org [accessed 8 March 2011].

Jiang, Z. (2004) Przewalski's Gazelle. China Forestry Publishing House, Beijing, China. [in Chinese].

JIANG, Z. (2008) Western eyes on China's wildlife. Wildlife Professional, 2, 63-64.

Jiang, Z., FenG, Z. \& WANG, Z. (1996a) Przewalski's gazelle in China. Conservation Biology, 10, 324-325.

Jiang, Z., Feng, Z., Wang, Z., Chen, L., Cai, P. \& Li, Y. (1995) Historical and current distributions of Przewalski's gazelles. Acta Theriologica Sinica, 15, 241-245. [in Chinese]

JiAnG, Z., GAO, Z. \& SUN, Y. (1996b) Current status of antelopes in China. Journal of Forestry Research, 7, 58-62.
JianG, Z., LeI, R., Han, X. \& Li, C. (2003) A review on the researches of Przewalski's gazelle. Chinese Journal of Zoology, 38, 129-132. [in Chinese]

JiAnG, Z., LI, D. \& Wang, Z. (2000) Population declines of Przewalski's gazelle around Qinghai Lake, China. Oryx, 34, 129-135.

Lei, R., Hu, Z., Jiang, Z. \& Yang, W. (2003) Phylogeography and genetic diversity of the critically endangered Przewalski's gazelle. Animal Conservation, 6, 361-367.

LeI, R., Jiang, Z. \& LiU, B. (2001) Group pattern and social segregation in Przewalski's gazelle (Procapra przewalskii) around Qinghai Lake, China. Journal of Zoology, 255, 175-180.

Li, C., Jiang, Z., Feng, Z., YAnG, X., Yang, J. \& Chen, L. (2009a) Effects of highway traffic on diurnal activity of the Critically Endangered Przewalski's gazelle. Wildlife Research, 36, 379-385.

LI, G. \& ZHAO, S. (2008) Eco-environmental protection and sustainable development in Qinghai Lake catchment. Environmental Science \& Technology, 31, 148-151. [in Chinese]

Li, Z., Jiang, Z. \& Beauchamp, G. (2009b) Vigilance in Przewalski's gazelle: effects of sex, predation risk and group size. Journal of Zoology, 277, 302-308.

LI, Z., JIANG, Z. \& LI, C. (2008) Dietary overlap of Przewalski's gazelle, Tibetan gazelle, and Tibetan sheep on the Qinghai-Tibet Plateau. Journal of Wildlife Management, 72, 944-948.

Liu, B. \& Jiang, Z. (2004) Dietary overlap between Przewalski's gazelle and domestic sheep in the Qinghai Lake Region and implications for rangeland management. Journal of Wildlife Management, 68, 241-246.

Mallon, D. \& JiANG, Z. (2009) Grazers on the plains: challenges and prospects for large herbivores in Central Asia. Journal of Applied Ecology, 46, 516-519.

Mallon, D. \& Kingswood, S. (2001) Antelopes. Part 4: North Africa, the Middle East, and Asia. Global Survey and Regional Action Plans. SSC Antelope Specialist Group. IUCN, Gland, Switzerland, and Cambridge, UK.

MANOR, R. \& SALtZ, D. (2004) The impact of free-roaming dogs on gazelle kid/female ratio in a fragmented area. Biological Conservation, 119, 231-236.

Maroney, R. (2005) Conservation of argali Ovis ammon in western Mongolia and the Altai-Sayan. Biological Conservation, 121, 231-241.

Morgan, E., Lundervold, M., Medley, G., Shaikenov, B., Torgerson, P. \& Milner-Gulland, E.J. (2006) Assessing risks of disease transmission between wildlife and livestock: the saiga antelope as a case study. Biological Conservation, 131, 244-254.

Preisser, E., Bolnick, D. \& Benard, M. (2005) Scared to death? The effects of intimidation and consumption in predator-prey interactions. Ecology, 86, 501-509.

Smith, K., Acevedo-Whitehouse, K. \& Pedersen, A. (2009) The role of infectious diseases in biological conservation. Animal Conservation, 12, 1-12.

Sun, F., LIU, C. \& LI, J. (2007) Inspection on population condition of Qinghai Lake district and policy suggestion. Northwest Population Journal, 28, 45-50. [in Chinese]

TANG, Z. \& WANG, Y. (2009) Status of land desertification in Qinghai Lake Basin and study on its synthetic control. Journal of Anhui Agricultural Science, 37, 2267-2269.

Thomas, L., Buckland, S., Burnham, K., Anderson, D., Laake, J., Borchers, D. \& Strindberg, S. (2002) Distance sampling. Encyclopedia of Environmetrics, 1, 544-552.

Thomas, L., Laake, J., Rexstad, E., Strindberg, S., Marques, F., Buckland, S. et al. (2009) Distance 6.o. Release 2. Research Unit for Wildlife Population Assessment, University of St Andrews, St Andrews, UK. Http://www.ruwpa.st-and.ac.uk/distance [accessed 25 November 2009]. 
WANG, X. (1991) Vertebrate Fauna of Gansu: Mammalia. Gansu Science and Technological Press, Lanzhou, China.

Wei, W. \& JiAng, Z. (1998) Preliminary study on population sizes and affecting factors of Przewalski's gazelles (Procapra przewalskii). Acta Theriologica Sinica, 18, 232-234. [in Chinese]

YANG, J., Jiang, Z., Zeng, Y., Turghan, M., FanG, H. \& Li, C. (2011) Effect of anthropogenic landscape features on population genetic differentiation of Przewalski's gazelle: main role of human settlement. PLoS ONE, 6(5): e20144.

Ye, R., Ping, C., PenG, M., Lu, X. \& MA, S. (2006) Investigation about the distribution and population size of Przewalski's gazelle (Procapra przewalskii) in Qinghai Province, China. Acta Theriologica Sinica, 26, 373-379. [in Chinese]

Zhang, R. \& WANG, Z. (1964) Report of Mammal Survey in the Area of Qinghai and Gansu. Science Press, Beijing, China. [in Chinese]

\section{Biographical sketches}

Chunlin $\mathrm{Li}$ is interested in animal behaviour and wildlife conservation, and is also studying vigilance behaviour of, and landscape connectivity for, Przewalski's gazelle. Zhigang Jiang's work focuses on animal conservation, particularly the threatened mammals of China. His research group studies Przewalski's gazelle, Tibetan gazelle and antelope, the Mongolian wild ass, argali, blue sheep, yak, goral, wild sika and Père David's deer, and recently the snow leopard, brown bear and tiger. Xiaoge Ping is involved in research on biodiversity conservation and internationsl trade in threatened species of wild fauna and flora. Jing Cai studies human-wildlife conflict in China. Zhangqiang You works on animal behaviour, with a focus on the mating system of Przewalski's gazelle. Chunwang $\mathrm{Li}$ is interested in animal behaviour and conservation. Yonglin $\mathrm{Wu}$ works in the Administration of the Qinghai Lake National Nature Reserve, with a special interest in the conservation of Przewalski's gazelle. 